\title{
A Comparative Study of Using Multimedia Annotation and Printed Textual Glossary in Learning Vocabulary
}

\author{
Dr Mohamad Jafre Zainol Abidin \\ School of Educational Studies, University of Science Malaysia (USM), Penang Island, \\ Malaysia \\ E-mail: Jafre@usm.my
}

Majid Pour-Mohammadi (PhD student/Corresponding author)

Dep. of English Language Translation, Islamic Azad University, Rasht Branch, Iran

Tel: +60-17-6054350Ｅ-mail: majid.pourmohammadi@gmail.com

Neda Sharbaf Shoar (PhD student)

School of Educational Studies, University of Science Malaysia (USM)

11800 Gelugor, Penang Island, Malaysia

E-mail: $\underline{n} \_$shoar@yahoo.com

See Toh Hoe Cheong (PhD student)

School of Educational Studies, University of Science Malaysia (USM), 11800 Gelugor,

Penang Island, Malaysia

E-mail: hcseetoh@gmail.com

Afif Mohamad Jafre (MA student)

School of Arts, University of Science Malaysia (USM), 11800 Gelugor, Penang Island,

Malaysia

E-mail: afifjafre@yahoo.com

Received: September 19, 2011 Accepted: October 28, 2011 Published: November 22, 2011

Doi:10.5296/ijld.v1i1.1070ＵRL: http://dx.doi.org/10.5296/ijld.v1i1.1070

\begin{abstract}
This study intends to evaluate the effectiveness of Electronic Glossary and Non-electronic Glossary in L2 vocabulary learning among a group of low proficiency learners of English. It also seeks to determine which glossary mode is effective to help learners in the recall and retention of the meanings learned. A multiple time-series design was adopted as the study involved the use of two sets of treatments as well as using three measurements in the forms of a pretest, a posttest and a delayed posttest. It was conducted over 4 weeks and 120 students from 2 different schools participated. Results suggest that Electronic Glossary in the form of Multimedia Annotation is more effective in the acquisition and learning of unknown vocabulary than Non-electronic Glossary in the form of Printed Textual Glossary. In addition,
\end{abstract}


it is also figured out that both modes of glossaries have some positive effects on the recall and retention rate of low proficiency students. The results are also discussed and some recommendations are finally provided.

Keywords: Multimedia annotation, Printed textual glossary, Vocabulary learning, Low proficiency, Language learner

\section{Introduction}

One of the most ambitious goals for a second or foreign language learner is to know all the vocabulary of that language (Nation, 2001). Therefore, it is useful to set learning goals and plan the learning of vocabulary. One way of planning and learning vocabulary is through the use of learning aids, especially glossary, both in the electronic and non-electronic modes.

Nation (2001) asserts that in the light of the rapid development in the use of computers in language learning, computers provide a very effective way of vocabulary learning, particularly in ensuring that learners' efforts are directed towards vocabulary that most need. Rezaee and Shoar (2011) also confirmed that the use of technology, and more specifically multimedia, can be of a great instructional value to instructors, program designers and language learners by providing learner-centred instructional settings which are updated and tailored to the needs of different learners and, at the same time, assisting the teachers by giving them sufficient materials that are practical and efficient. Studies on vocabulary learning with the use of the computer have confirmed the effectiveness of electronic glossary in L2 vocabulary learning among learners in general (Al-Seghayer, 2001; Laufer \& Hill, 2000; Lim, 2003). Whilst this is true, computers and computer based learning are not accessible to a majority of learners in Malaysia. As such there is a need to find out the alternative to electronic glossary. With regard to this, therefore, this study seeks to determine whether electronic glossary is more effective than non-electronic glossary in L2 vocabulary learning.

\subsection{Objectives}

The main objectives of this study are:

a) To evaluate the effectiveness of Electronic Glossary and Non-electronic Glossary in the vocabulary learning of a group of low proficiency ESL learners

b) To determine which mode of glossary is more effective in the recall and retention of new vocabulary by low proficiency ESL learners

It tries to compare the efficiency of two different annotation modes, electronic and non-electronic glossary, in vocabulary acquisition and determine which mode is more effective in aiding vocabulary learning among a group of L2 learners with low proficiency in English.

\subsection{Research Questions}

The study mainly aims at finding the answers to the following questions:

1. Is there any difference between the scores of group using Electronic and Non-electronic Glossaries in the recall of the meaning of vocabulary items?

2. Is there any difference between the scores of group using Electronic and Non-electronic Glossaries in retaining of the meaning of the vocabulary items? 
It is hoped that this study would encourage learners to place more emphasis on learning vocabulary in general and on using glossary to learn vocabulary in particular. It also provides feedback to both teachers and parents on the benefits in the use of electronic compared to non-electronic glossaries to aid learners, especially those with low proficiency in learning vocabulary effectively.

\section{Literature Review}

The importance of vocabulary for overall foreign language learning is the basis of studies in vocabulary learning (Nation, 2001; Nikolova, 2002). Many researchers believe that facing entirely new words is the main obstacle in learning English (Anderson \& Freebody, 1981). Based on the high-imagery concrete vocabulary learning, Kellogg and Howe (1971) believe that foreign words, while associated with images or actual objects, are learned more easily than those without such supportive information.

Terrell (1986) asserted that combining an unknown L2 word with a visual representation bypasses a direct translation and facilitates vocabulary learning. Underwood (1989, p. 19) also notes that "we remember images better than words, hence we remember words better if they are strongly associated with images". Studies by other researchers also propose that words in foreign language learning associated with aural or written translations and images are learned more easily than those accompanied by pictures or text alone (Oxford \& Crookall, 1990). For example, they suggest that the combination of picture and text provides the grounds for accessing more parts of the brain which leads to greater depth of processing than when text is processed alone.

The studies on the procedures of learning indicate that information is cognitively processed through visual or verbal channels (Mayer, 1997). As it is assumed by dual processing strategy (Mayer \& Moreno, 2002), individuals develop mental pictorial representations of graphic input and mental verbal representations of linguistic input. It is believed that the presence of both pictorial and verbal cues can simultaneously facilitate learning. This particularly happens when the corresponding visual and verbal representations are contiguously present in working memory. Mayer's (1997) generative theory of multimedia learning states that in order to comprehend a text in a multimedia format meaningfully, learners must select relevant pictorial and/or linguistic information from it, organize the input into coherent visual and verbal mental representations, and then integrate the latter by constructing referential connections between the two.

Hilton and Hyder (1995) propose numerous ways for learners to acquire vocabulary in L2 language learning such as the use of dictionaries and glosses. However, one of the main problems with dictionary use (particularly the conventional printed dictionaries) is that it can become a boring activity for L2 language learning. Other problems include the increase in the time taken to complete a reading task, the use of dictionaries by high ability learners when they do not necessarily need to, the loss of faith by learners in their inferring skills and the inaccurate application of the meaning according to context (Nation, 2001).

As an alternative to look up an individual word in a dictionary, the use of a glossary can save the learner much time. The marginal glossary, a non-electronic form of glossary is also effective in vocabulary learning. Nation (2001) suggests that the learning of vocabulary is 
more efficient when learners read without deliberately focusing on new vocabulary. This is possible when marginal glossary is provided for learners during vocabulary learning because 'marginal glossary in text seems to improve comprehension, recall and retention of meaning' (Nation \& Newton, 1997, p. 253).

In addition to the use of the dictionary or non-electronic glossary, the use of computer technology in language learning can also aid in vocabulary acquisition. The development in the use of computers has had considerable consequence on language learning and teaching methods. An aspect of computer-assisted language learning (CALL) in vocabulary acquisition, which is gaining attention over the past years, is the electronic glossing of individual words through different modalities (Al-Seghayer, 2001). In his study on modes of multimedia annotation, Al-Seghayer discovered that a video clip is more effective in teaching unknown vocabulary words than a still picture. Several researchers have also studied and provided data in favor of the use of computerized glosses in L2 vocabulary acquisition (Jones, 2004; Nikolova, 2002; Parks et al., 2003). Nevertheless, in the Malaysian local context, studies that look at this issue are very rare.

Huang (2007) argues that provision of glosses in reading can facilitate vocabulary learning by directing readers' attention towards the meaning of target words when they encounter the word forms, as long as the annotation is not intrusive. Various studies have investigated the effectiveness of multi-mode glosses over the single-mode ones, and if so, which combination of multi-mode glosses is most effective. Chun and Plass (1996) performed a series of studies on multimedia glosses and vocabulary acquisition. They figured out that the combination of text and picture glosses was more effective than text-only or text-plus-video glosses.

The relative effectiveness of multi-mode glosses over single-mode glosses was confirmed in Plass et al. (1998). The study also investigated the effects of different gloss types in a multimedia context indicating whether learners are more likely to learn words when they are presented with both verbal (textual) and visual (picture) glosses or when they receive one mode or none. The study found that the performance was better when the learners used both visual and verbal modes of glosses, in comparison to selecting only one mode, and finally the worst when they did not select any. The results also indicated that the combination of text and picture was better than that of text and video for learning the words.

To investigate and confirm the effectiveness of the combination of text and picture glosses over that of text and video glosses, Al-Seghayer (2001) compared the two gloss combinations. The results revealed that the combination of text and video were more effective than that of the text and picture. Ridder (2002) also investigated the effect of the signaling-mode of electronic glosses in online texts, i.e., presented digitally on a computer screen, on the user's reading process, incidental vocabulary learning, and text comprehension. The findings of her study indicated that reading a text with highlighted hyperlinks, readers are significantly more willing to consult the gloss and this does not slow down the reading process, rather affects text comprehension, and increases the vocabulary learned incidentally. She implies that the reading task does not seem to alter the clicking behavior of the students but seems to influence the reader's vocabulary learning i.e., a content-oriented reading task decreases the reader's attention for vocabulary. 
One study by Lim (2003) looked at the effects of two different modes of electronic glossary in L2 vocabulary on Malaysian learners. The study focused on a group of elementary learners whose proficiency in English was above average. The study found that electronic Textual Glossary was more effective than Multimedia Annotation in the recall of new vocabulary items while there seemed to be no difference between the two modes of electronic glossaries in terms of retention. Lim's (2003) findings are encouraging. The fact is that the use of the computer in Malaysia is very limited due to various reasons and a large number of Malaysian learners do not have above average proficiency in English. Although approximately $75 \%$ of students pass the English subject at the PMR level (lower secondary public examination), it is also generally understood that the passing mark is low.

Given this situation, there is a need to look at the issue of vocabulary learning of the learners with low proficiency in English. Moreover, the use of textual glossary needs to be looked into because not all learners have access to a computer or even a good dictionary all the time. There is a need to look at whether ESL learners with low proficiency could benefit more from electronic or non-electronic glossary in vocabulary acquisition.

\section{Research Design}

This study adopts the multiple time-series design as it involves the use of two sets of treatments which are compared using three measurements in the form of a pretest, a posttest and a delayed posttest. It was conducted over a 4-week period in two different schools where there were a total of 120 students. The students were selected by their respective teachers based on the results of their past PMR. All the treatments were carried out by the respective English language teachers during their lesson time.

A modified quasi-experimental design was used. It involves a single-factor two-level design which uses a single independent variable. The independent variable in the study is in the form of glossary, which is either electronic or non-electronic glossary. The electronic glossary in this study is the Multimedia Annotation which provides the meaning of each lexical item in the form of text, picture and sound. The non-electronic glossary is essentially the Printed Textual Glossary which is an annotation printed on paper where the meaning of words is presented in text only.

It is worth mentioning that the term 'recall' is used to refer to the ability of the subjects to use the target lexical items correctly in the posttest, administered immediately after the treatment. On the other hand, 'retention' is the ability of the subjects to use the target lexical items correctly after a lapse of two weeks. To gauge retention, the subjects were asked to sit for a delayed posttest. The delayed posttest was administered two weeks later in order to avoid any further disruptions to the students' classroom learning schedule and also it followed the time sequence of the students' first monthly exam. All the subjects were assumed to have similar ability in English, which is low proficiency since all of them had not passed their English Language paper in the PMR examination.

\section{Results and Discussion}

There were similarities and differences between the findings of the two modes of glossaries for Passage A and Passage B. For both passages, Multimedia Annotation appears to be more 
effective than Printed Textual Glossary in the recall of new lexical items. The recall rate for the Multimedia Annotation group was clearly higher in Passage A, while the recall rate for Passage $\mathrm{B}$ was as high compared to the Printed Textual Glossary group. However, the retention rate was different for both passages. For Passage A, Printed Textual Glossary was better but for Passage B, Multimedia Annotation had a small advantage over Printed Textual Glossary (Table4.1).

Table 4.1: Mean Scores of both Groups on Passages A and B (Posttest)

\begin{tabular}{|l|l|l|l|}
\hline \multicolumn{2}{|l|}{} & $\begin{array}{l}\text { Mean Score } \\
\text { (Question 1) }\end{array}$ & $\begin{array}{l}\text { Mean Score } \\
\text { (Question 2) }\end{array}$ \\
\hline $\begin{array}{l}\text { Multimedia } \\
\text { Annotation Group } \\
\text { (Electronic Glossary) }\end{array}$ & Passage (A) & $42.67 \%$ & $31.67 \%$ \\
\cline { 2 - 4 } $\begin{array}{l}\text { Printed Textual } \\
\text { Group } \\
\text { (Non-electronic } \\
\text { Glossary) }\end{array}$ & Passage (B) & $33.67 \%$ & $24.67 \%$ \\
\cline { 2 - 4 } & Passage (B) & $28.67 \%$ & $22.33 \%$ \\
\hline
\end{tabular}

\subsection{Discussion of Research Question 1-Ability to Recall Meaning}

The results show that for both passages, subjects who used Multimedia Annotation generally did better than those who used Printed Textual Glossary. The mean obtained for correct answers in the posttest for Passage A is $42.67 \%$ for Multimedia Annotation and only $31.67 \%$ for Printed Textual Glossary. This shows that Multimedia Annotation is more effective than Printed Textual Glossary in recalling vocabulary items. However it should be noted that Printed Textual Glossary is also useful albeit at a lower percentage. The results obtained from the mean scores of the learners on the posttest indicate that it is highly probable that Multimedia Annotation is more effective than Printed Textual Glossary.

With regard to Passage $\mathrm{B}$, the results again indicate Multimedia Annotation to be more effective than Printed Textual Glossary in the subjects' ability to recall the meaning of the items. The mean for the posttest shows that the mean score for Multimedia Annotation is $33.67 \%$, slightly higher than the mean score for Printed Textual Glossary, which is $28.67 \%$.

The results reveal that both Multimedia Annotation and Printed Textual Glossary have some effects on the recall of lexical items learned. The effects of Printed Textual Glossary may be due to the reciprocal relationship between visual information, non-visual information and reading. Where Printed Textual Glossary is concerned, there is only non-visual information in the form of text. In the absence of visual information, the non-visual information functions full responsibility in the learning process. It is also evident that Multimedia Annotation is more effective than Printed Textual Glossary. According to Paivio's (1986) dual-coding theory, the use of both verbal and non-verbal material enables the learners to 'build referential connections between the visual representation and the verbal representation in short-term memory' (Chun \& Plass, 1997, p. 67), thus enabling a better recall ability. 
Concerning the results of Lim's (2003) study, the results of this study indicate electronic glossary is effective in vocabulary learning for both high and low proficiency learners. Where students with high proficiency are concerned, Lim's results indicate a much higher percentage of recall as compared to this study on low proficiency learners. The low achievement of the low proficiency learners may possibly be due to the lower language proficiency and lower intelligence factors (as compared to Lim's subjects), which are among the variables for selection of appropriate strategies in Gu's (2003) person-task-context-strategy vocabulary acquisition theory. The results are also consistent with previous studies conducted by Al-Seghayer (2001), Laufer and Hill (2000), and Nikolova (2002).

\subsection{Discussion of Research Question 2-Ability to Retain Meaning}

It was discovered that for both modes of glossaries, the number of subjects who were able to recall the meaning dropped around $11 \%$ for Passage A. The scores in the delayed posttest showed that Multimedia Annotation is better than Printed Textual Glossary in the retention of lexical items learned. The mean for Multimedia Annotation is $31.67 \%$ while the mean for Printed Textual Glossary is $22.33 \%$.

The results for Passage B again confirmed that Multimedia Annotation is better than Printed Textual Glossary in the retention of lexical items learned. However, the percentage of subjects who were able to retain the meaning dropped more in these two treatments. This could be due to the higher difficulty of the passage (used in the two treatments) which affected the target learning task and caused distractions in the selection of learning strategies (Gu, 2003). In the delayed posttest, the mean for Multimedia Annotation is $24.67 \%$ while the mean for Printed Textual Glossary is $18.67 \%$. This shows that Multimedia Annotation is still better than Printed Textual Glossary despite the low scores for both modes of glossaries. This is because the subjects' proficiency level was low and the scores in the pretest (6.2\%) showed that only very few of the subjects know the meaning of the stimulus items used. Thus, the treatments did have some effects on the subjects.

\section{Conclusion and Pedagogical Recommendations}

The objective of this study is to evaluate the effectiveness of Electronic Glossary and Non-electronic Glossary in L2 vocabulary learning among a group of low proficiency learners of English. It also attempts to determine which glossary mode is effective to aid learners in the recall and retention of the meanings learned. The findings suggest that Electronic Glossary in the form of Multimedia Annotation is more effective in the acquisition and learning of unknown vocabulary than Non-electronic Glossary in the form of Printed Textual Glossary. In addition, it is also grasped that both modes of glossaries have some positive effects on the recall and retention rate of low proficiency students who utilized the two different modes of glossaries.

The pedagogical implications include addressing the design of multimedia instruction for second language learning, glossary modes for vocabulary learning in particular, and teaching the ways to use the modes of glossary in general. Although this study shows that Multimedia Annotation is the better mode of glossary, Printed Textual Glossary should not be overlooked as it also has some positive effects on vocabulary learning. Therefore, course designers, 
teachers, program developers and book writers may want to consider using the information in the development of course materials and the selection of teaching methodology.

In particular, teachers should encourage students to use both the electronic and the non-electronic forms of glossary. Teachers should also make it a point to explain to students how the modes of glossary aid in effective language learning. Thus, teachers should encourage students to make use of the available mode of glossary to find the meaning of difficult or unknown words. As for instructors and program developers for vocabulary learning applications, they should consider including interesting and relevant visual materials in their programs in order to increase learners' motivation to allocate the required mental effort to learn the unknown words.

\section{References}

Al-Seghayer, K. (2001). The effect of multimedia annotation modes on 12 vocabulary acquisition: A comparative study. Language Learning \& Technology, 5(1), 202-232. [Online] Available: http://llt.msu.edu/vol5num1/alseghayer/default.html (Sep. 25, 2011)

Anderson, R. C. \& Freebody, P. (1981). Vocabulary knowledge. In J. T. Guthrie (Ed.). Comprehension and teaching: Research reviews (pp. 77-117). Newark, NJ: International Reading Association

Chun, D. \& Plass, J. (1996). Effects of multimedia annotations on vocabulary acquisition. Modern Language Journal, 8(2), 183-198. [Online] Available: http://www.jstor.org/pss/328635 (Oct. 25, 2011)

Chun, D., \& Plass, J. (1997). Research on text comprehension in multimedia environments. Language Learning \& Technology, 1(1), 60-81. [Online] Available: http://www.llt.msu.edu/vol1num1/chun_plass/default.html (Sep. 25, 2011)

Gu, P. Y. (2003). Vocabulary learning in a second language: Person, task, context and strategies. TESL-EJ, 7(2), 1-25. [Online] Available: http://www.tesl-ej.org/wordpress/issues/volume7/ej26/ej26a4/ (Aug. 25, 2011)

Hilton, C. \& Hyder, M. (1995). Getting to grips with vocabulary. Kuala Lumpur: Golden Books Centre Sdn. Bhd.

Huang, H. T., \& Liou, H. C. (2007). Vocabulary learning in an automated graded reading program. Language Learning \& Technology, 11(3), 64-82. [Online] Available: http://ltt.msu.edu/vol11num3/huangliou/default.html (Oct. 25, 2011)

Jones, L. (2004). Testing L2 vocabulary recognition and recall using pictorial and written test items. Language Learning and Technology, 8(3), 122-143.

Kellogg, G. \& Howe, M. J. (1971). Using words and pictures in foreign language learning. Alberta Journal of Educational Research, 17(2), 87-94.

Laufer, B. \& Hill, M. (2000). What lexical information do 12 learners select in a call dictionary and how does it affect word retention? Language Learning and Technology, 3 (2), 58-76. [Online] Available: http://www.llt.msu.edu/vol3num2/laufer-hill (Sep. 11, 2011) 
Lim, T. H. (2003). The effectiveness of the use of textual glossary and multimedia annotation in 12 vocabulary learning: A case study of elementary learners of English. Master Thesis, School of Humanities, University of Science Malaysia (USM).

Mayer, R. E. (1997). Multimedia learning: Are we asking the right questions? Educational Psychologist, 32(1), 1-19. http://dx.doi.org/10.1207/s15326985ep3201_1

Mayer, R. E. \& Moreno, R. (2002). Aids to computer-based multimedia learning. Learning and Instruction, 12, 107-110. http://dx.doi.org/10.1016/S0959-4752(01)00018-4

Nation, P. (2001). Learning vocabulary in another language. Cambridge: Cambridge Universtity Press.

Nation, P. \& Newton, J. (1997). Teaching vocabulary. In J. Coady and T. Huckin (Eds.). Second language vocabulary acquisition, (238-254). Cambridge: Cambridge University Press.

Nikolova, O. R. (2002). Effects of students' participation in authoring of multimedia materials on student acquisition of vocabulary. Language Learning \& Technology 6(1), 100-122. [Online] Available http://llt.msu.edu/vol6num1/nikolova/default.html (Aug. 22, 2011)

Oxford, R. \& Crookall, D. (1990). Vocabulary learning: A critical analysis of techniques. TESL Canada Journal, 7(2), 9-30. [Online] Available: http://www.teslcanadajournal.ca/index.php/tesl/article/view/566 (May 25, 2011)

Paivio, A. (1986). Mental representations. New York: Oxford University Press.

Parks S., Huot, D., Hamers, J. \& Lemonnier, F. H. (2003). Crossing boundaries: Multimedia technology and pedagogical innovation in a high school class. Language Learning and Technology, 7(1), 28-45. [Online] Available: http://www.llt.msu.edu/vol7num1/pdf/parks.pdf (Oct. 15, 2011)

Plass, J. L., Chun, D. M., Mayer, R. E. \& Leutner, D. (1998). Supporting visual and verbal learning preferences in a second language multimedia learning environment. Journal of Educational Psychology, 90(1), 25-36. http://dx.doi.org/10.1037/0022-0663.90.1.25

Rezaee, A. \& Shoar, N. (2011). Investigating the effect of using multiple sensory modes of glossing vocabulary items in a reading text with multimedia annotations. English Language Teaching, 4(2), 25-34. [Online] Available: http://journal.ccsenet.org/index.php/elt/article/view/10759 (Oct. 20, 2011)

Terrell, T. (1986). Acquisition in the natural approach: the binding/access framework. The Modern Language Journal, 70(3), 213-227. [Online] Available: http://www.jstor.org/pss/326936 (Sep. 12, 2011)

Underwood, J. (1989). Hyper card and interactive video. CALICOL, 6(3), 7-20. 